\title{
Comparison of Truview Evo2 and McCoy Laryngoscope for Tracheal Intubation Using Malleable or Straight or Directable Stylet
}

\author{
Dr. Atul T. Walzade ${ }^{1}$, Dr. Shashikant Shinde ${ }^{2}$, Dr. R. D. Patel ${ }^{3}$, \\ Dr. SeemaWaidande ${ }^{4}$, Dr. Manali Nadkarni ${ }^{2}$ \\ ${ }^{I}$ (Assistant Professor, Department Of Anaesthesiology, Seth G.S. Medical College \&K.E.M. Hospital, India.) \\ ${ }^{2}$ (Additional Professor, Department Of Anaesthesiology, Seth G.S. Medical College \&K.E.M. Hospital, India. \\ ${ }^{3}$ (Professor, Department Of Anaesthesiology, Seth G.S. Medical College \&K.E.M. Hospital, India.) \\ ${ }^{4}$ (Ex Resident, Department Of Anaesthesiology, Seth G.S. Medical College \&K.E.M. Hospital, India.)
}

\begin{abstract}
Anesthesiologists as a clinician is always ready with various plan and instrument to safeguard the airway. He is ready with backup plan whether it is anticipated or unanticipated difficult airway. Unusual anatomic configurations may be encountered when the airway is difficult itself. Best accessories such as bougie, stylet, prism, angle adaptorand mirrors as well as various methods of laryngoscopy such as modified straight blade laryngoscopes were tried to overcome the problem of difficult intubation. Anesthesiologist should be familiar and master in handling these instrument. Our study was randomized prospectively consisting of 300 patients randomly allotted into 6 groups with 50 in each group. Combination of either Truview laryngoscope or McCoy blade with malleablestylet, straight stylet and directable stylet done. Parameter studied was duration of laryngoscopy and intubation, number of attempt for successful intubation, Cormack-Lehane grading improvement either by elevation of tip of McCoy blade or after cricoid pressure in Truview laryngoscope. Complications like trauma to any oropharyngeal structurenoted.

In this prospective randomized clinical study, we observed that the duration of intubation was prolonged in the Truview group as compared to the McCoy group but the laryngoscopic optimal view which was determined by Cormack-Lehane grading was better with the Truview group. Amongst the stylet the directable stylet reduced the duration of intubation in both the McCoy and the Truview group as compared to malleable and straight stylet. The number of patients who were intubated in the $1^{\text {st }}$ attempt were more in the McCoy group as compared to the Truview group. Also there was no statistically significant difference between the rates of complications amongst the groups.
\end{abstract}

Keyword: Truview, McCoy, Direcable stylet, Malleable stylet, straight stylet.

\section{Introduction}

The anesthesiologists play a very important role in health care, rendering patient free from pain either in the form of regional anesthesia, local anesthesia or general anesthesia to facilitate surgical procedure.The primary responsibility of the anesthesiologists as a clinician is to safeguard the airway i.e. to preserve and protect it during induction, maintenance and recovery from the state of anesthesia and in the event of loss of the airway, it should be promptly re-established before the individuals suffers irreversible injury from inadequate or compromised oxygenation. Various methods have been used to secure an airway e.g. orotracheal, nasotracheal and tracheostomy of which an orotracheal intubation is one which is most commonly used. Orotracheal intubation using a laryngoscope is a commonly practice method. Numbers of modifications and experiments have been done to improve the laryngoscopic view of the glottis. The different types of laryngoscopes give more or less similar results. Unusual anatomic configurations may be encountered when the airway is difficult itself. In these situations the intubation is a challenge to an anesthesiologist. During anesthesia airway catastrophes can occur due to variety of reasons such as respiratory obstruction, difficult intubation or esophageal intubation. So airway assessment is one of the tools to anticipate difficult airway and manage accordingly. Best accessories such as bougie, stylet, prism, angle adaptorand mirrors as well as various methods of laryngoscopy such as modified straight blade laryngoscopes were tried to overcome the problem of difficult intubation. Some patients are difficult to intubate after induction of anaesthesia without preoperative signs of difficult airway ${ }^{1}$. To overcome this difficulty, the use of stylet is recommended for patient with full stomach ${ }^{2}$. However gum elastic bougie is routinely used as an aid to difficult intubation worldwide ${ }^{3,4 .}$ There are many studies comparing different types of stylet and bougie in general and in a difficult intubation scenario. The McCoy laryngoscope (1993) is a modification of standard Macintosh blade. It has a hinged tip that is operated by a lever mechanism on the back of the handle. It allows elevation of the epiglottis while reducing the amount of force required. This blade has been shown to improve the view at laryngoscopy in difficult intubations ${ }^{5}$ The Truview EVO2 
(Truphatek Holdings Ltd, Netanya, Israel), enables an indirect view of the vocal cords. The Truview EVO2 blade is based on a combination of an optical system with a specially profiled $12.8 \mathrm{~mm}$ slim steel blade. The optical apparatus provides a $42^{\circ}$ deflection view through a $15-\mathrm{mm}$ eyepiece.

Our study is about comparing Truview laryngoscope and McCoy laryngoscope with malleable, straight and directablestylet regarding their differences in glottis view, attempts of laryngoscopy, hemodynamic changes, duration and complications.

\section{Materials And Methods}

A study was randomized prospectively consisting of 300 patients posted for surgical procedure under general anesthesia. The Ethics Committee approval was taken to conduct the study. Patients in the age group of 18-60 years, belonging to ASA grade I and II with MPC grade I and II who were undergoing any surgical procedure under general anaesthesia with endotracheal intubation are included. Patients with anticipated difficult intubation and Patients at risk of pulmonary aspiration of gastric contents or with pathology in neck, upper respiratory tract and upper alimentary tract are excluded.

Patients randomly allotted into 6 groups with 50 in each group.

Group 1/TM-Truview laryngoscope with malleable stylet

Group 2/TS-Truview laryngoscope with straight stylet

Group 3/TD-Truview laryngoscope with directable stylet

Group 4/MM-McCoy laryngoscope with malleable stylet

Group 5/MS-McCoy laryngoscope with straight stylet

Group 6/MD-McCoy laryngoscope with directable stylet

All patients were explained about the nature of the study and a written informed valid consent on a separate consent form was taken from the patient and his / her relative. Any queries from patient were cleared.

Patients were randomly allocated to undergo laryngoscopy using Truview EVO2 (figure 5) or McCoy(figure4) laryngoscopes followed by intubation using malleable(figure 1)or straight(Figure 2)or directable stylet(figure 3) using chit in the box technique.

After attaching monitors Pulse oximeter, cardioscope, sphygmomanometer baseline pulse rate, blood pressure, ECG were recorded. - 18G intravenous angiocatheter was used to secure IV line. - Patient waspremedicated with Inj. Granisetron $1 \mathrm{mg}$ IV and Inj. Ranitidine $50 \mathrm{mg}$ IV. - IV Ringers lactate was started.Patient was then premedicated with Inj.Midazolam $0.03 \mathrm{mg} / \mathrm{kg}$ IV or Inj. $0.6 \mathrm{mg} / \mathrm{kg}$ IV .After preoxygenation, patients were induced with Inj. Propofol $2 \mathrm{mg} / \mathrm{kg}$ IV and Inj. vecuronium $0.1 \mathrm{mg} / \mathrm{kg}$ IV .Patient were oxygenated for 5 minutes with $100 \%$ oxygen. Adequate muscle relaxation and adequate depth of anaesthesia was achieved. Anaesthesia was maintained with Oxygen and Nitrous Oxide in 50:50 ratio and Isoflurane with intermittent boluses of Inj. vecuronium.

The patients head and neck were kept in optimal intubating position during intubation. Laryngoscopy was performed using either Truview or McCoy laryngoscope. In this study Cormack and Lehane grading was taken into consideration, which is as follows:

Grade 1: full view of glottis.

Grade 2: Only posterior extremity of glottis visible.

Grade 3: Only epiglottis seen.

Grade 4: No glottis or epiglottis structure visible.

If view was not grade 3 with Truview laryngoscope, external laryngeal pressure was applied to the larynx to improve it. Also while using McCoy laryngoscope, the tip of the blade was elevated to improve the laryngeal view. After recording the best view of larynx, a brief period of controlled hyperventilation with $100 \%$ oxygen was resumed.

Following this tracheal intubation was attempted with a suitable size endotracheal tube (portex, cuff) using either malleable or straight or directable stylet. The stylet was withdrawn and the breathing circuit was connected to the tube. Successful tracheal intubation was confirmed by appearance of mist in the endotracheal tube, chest wall movement, auscultation and capnography. The lungs were ventilated with Oxygen in between the attempts.

An attempt in which the patient could not be intubated or more than 3 attempts were required was considered to be a failed intubation and that patient was excluded from the study.

Duration of laryngoscopy: The time taken from removal of face mask and insertion of laryngoscope blade between the teeth to visualization of vocal cords and noting the Cormack and Lehane grading.Duration of intubation attempt: The time taken from visualization of vocal cords and passing the endotracheal tube in the trachea to confirmation of its tracheal placement by appearance of mist in the endotracheal tube, chest wall movement, etc. When tracheal intubation failed at the first attempt, but succeeded at the second attempt, the sum 
of the time taken for the first and the second attempts was noted similarly if succeeded at third attempt, the sum of time taken for first, second and third attempt was noted (excluding the ventilation period between attempts). After successful endotracheal intubation, the tube was attached to the circuit, patient was ventilated with $100 \%$ oxygen. Tube position was confirmed with auscultation of chest at 5 points, capnography. Maintenance of oxygen saturation, pulse rate, blood pressure. Endotracheal tube was fixed at appropriate mark. Complications like trauma to lips, trauma to pharynx, toothfall, toothloosening,secretion,laryngospasm, bronchospasm, desaturation, oesophageal intubation was noted and recorded. The statistical analysis of the study was carried out by SPSS and GraphPadInstat. ANOVA application, Chi square test, students t test wherever applicable

\section{Result}

Table 1: Demography Characteristics

\begin{tabular}{|l|l|l|l|l|l|l|}
\hline Parameters & $\begin{array}{l}\text { Group1 } \\
\text { (TM) }\end{array}$ & $\begin{array}{l}\text { Group2 } \\
\text { (TS) }\end{array}$ & $\begin{array}{l}\text { Group3 } \\
\text { (TD) }\end{array}$ & $\begin{array}{l}\text { Group4 } \\
\text { (MM) }\end{array}$ & $\begin{array}{l}\text { Group5 } \\
\text { (MS) }\end{array}$ & $\begin{array}{l}\text { Group6 } \\
\text { (MD) }\end{array}$ \\
\hline No.of patients & 50 & 50 & 50 & 50 & 50 & 50 \\
\hline $\begin{array}{l}\text { Age (yeas) } \\
\text { Mean }\end{array}$ & 42.82 & 45.78 & 40.88 & 43.02 & 44.76 & 41.36 \\
SD & 11.00 & 11.44 & 12.88 & 10.85 & 9.96 & 8.52 \\
Range & $18-65 \mathrm{yrs}$ & $18-65 \mathrm{yrs}$ & $18-65 \mathrm{yrs}$ & $18-65 \mathrm{yrs}$ & $18-65 \mathrm{yrs}$ & $18-65 \mathrm{yrs}$ \\
\hline SEX \% & $26(52 \%)$ & $21(42 \%)$ & $22(44 \%)$ & $26(52 \%)$ & $19(38 \%)$ & $24(48 \%)$ \\
Male & $24(48 \%)$ & $29(58 \%)$ & $28(56 \%)$ & $24(48 \%)$ & $31(62 \%)$ & $26(52 \%)$ \\
Female & $33(66 \%)$ & $25(50 \%)$ & $\begin{array}{l}25(50 \%) \\
25(50 \%)\end{array}$ & $\begin{array}{l}33(66 \%) \\
17(34 \%)\end{array}$ & $\begin{array}{l}27(54 \%) \\
23(46 \%)\end{array}$ & $\begin{array}{l}30(60 \%) \\
20(40 \%)\end{array}$ \\
\hline $\begin{array}{l}\text { ASA Grade \% } \\
2\end{array}$ & $17(34 \%)$ & $25(50 \%)$ & $25(20)$
\end{tabular}

Table 1shows all six group are comparable in terms of age, sex and ASA grading as p value is $>0.05$

Table 2: Comparison of Airway assessment between the Groups

\begin{tabular}{|c|c|c|c|c|c|c|}
\hline Parameters & $\begin{array}{l}\text { Group } 1 \\
\text { (TM) }\end{array}$ & $\begin{array}{l}\text { Group } 2 \\
\text { (TS) }\end{array}$ & $\begin{array}{l}\text { Group3 } \\
\text { (TD) }\end{array}$ & $\begin{array}{l}\text { Group4 } \\
\text { (MM) }\end{array}$ & $\begin{array}{l}\text { Group5 } \\
\text { (MS) }\end{array}$ & $\begin{array}{l}\text { Group6 } \\
\text { (MD) }\end{array}$ \\
\hline No. Of patients & 50 & 50 & 50 & 50 & 50 & 50 \\
\hline \multicolumn{7}{|l|}{ MH } \\
\hline Distance $(\mathrm{cm})$ & & & & & & \\
\hline Mean & 5.14 & 5.15 & 5.19 & 5.11 & 5.13 & 5.12 \\
\hline SD & 0.33 & 0.29 & 0.34 & 0.32 & 0.33 & 0.32 \\
\hline \multicolumn{7}{|l|}{ MT } \\
\hline $\begin{array}{l}\text { Distance }(\mathrm{cm}) \\
\text { Mean }\end{array}$ & 6.03 & 6.05 & 6.08 & 5.96 & 6.03 & 6 \\
\hline SD & 0.42 & 0.29 & 0.46 & 0.33 & 0.46 & 0.40 \\
\hline \multicolumn{7}{|l|}{ MS } \\
\hline Distance $(\mathrm{cm})$ & & & & & & \\
\hline Mean & 14.72 & 15.04 & 14.98 & 14.90 & 15.08 & 15 \\
\hline SD & 0.67 & 0.66 & 0.79 & 0.58 & 0.69 & 0.69 \\
\hline \multicolumn{7}{|l|}{ MPC grade } \\
\hline mean & 1.44 & 1.44 & 1.40 & 1.56 & 1.48 & 1.40 \\
\hline SD & 0.50 & 0.50 & 0.49 & 0.50 & 0.50 & 0.49 \\
\hline
\end{tabular}

table 2showsthere is no difference in all group in term of airway assessment by measurement of Mentohyoid distance, Mentothyroid distance and Mentosternal distanceThese values are comparable and $\mathrm{p}$ value is $>0.05$.

Table 3: Comparison of Cormack Lehane laryngoscopicoptimal view between the groups.

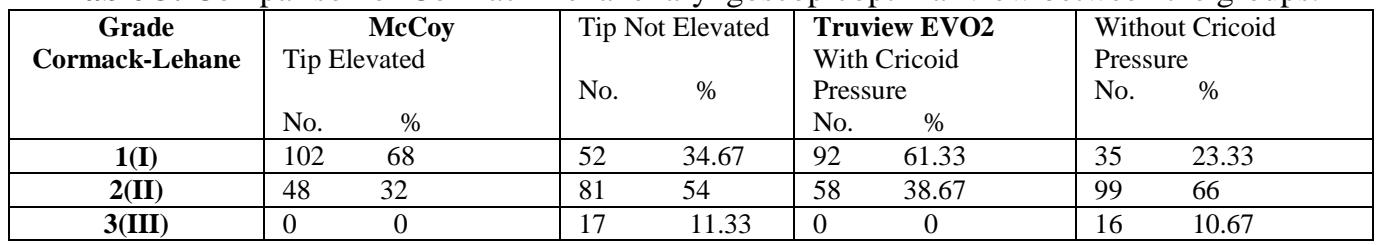


Comparison Of Truview Evo2 And Mccoy Laryngoscope For Tracheal Intubation Usin.....

\begin{tabular}{|l|ll|ll|}
\hline & \multicolumn{2}{|l|}{ McCoy } & \multicolumn{2}{l|}{ Truview } \\
& No & $\%$ & No & $\%$ \\
\hline Improved & 67 & 44.67 & 73 & 48.67 \\
\hline No Change & 83 & 55.34 & 77 & 51.34 \\
\hline
\end{tabular}

Table 3shows number of cases with CL grading 1,2 and 3 in the McCoy group without the tip elevation of the blade and second part of table shows number of cases after tip elevationin which CL grade improvement or no change occurred.

Table 4: Comparison between the Groups for T1 time, T2 time and total duration for intubation.

\begin{tabular}{|c|c|c|l|}
\hline Groups & $\begin{array}{c}\text { Mean Time T1 } \\
\overline{\mathrm{X}}_{ \pm \mathrm{SD}} \\
(\text { Seconds })\end{array}$ & $\begin{array}{c}\text { Mean Time T2 } \\
\left(\overline{\mathrm{X}}_{ \pm \mathrm{SD}}\right) \\
(\text { Seconds) }\end{array}$ & $\begin{array}{l}\text { Mean Time [total } \\
\text { duration] } \\
\left(\ddot{\mathrm{X}}_{ \pm} \text {SD) }\right. \\
(\text { Seconds })\end{array}$ \\
\hline Group 1(TM) & $34.5 \pm 7.08$ & $46 \pm 7.07$ & $80.5 \pm 12.54$ \\
\hline Group 2(TS) & $32.5 \pm 7.16$ & $43 \pm 7.42$ & $75.5 \pm 11.12$ \\
\hline Group 3(TD) & $28.9 \pm 7.16$ & $42 \pm 9.47$ & $70.9 \pm 13.08$ \\
\hline Group 4(MM) & $22.2 \pm 6.4$ & $38.9 \pm 8.59$ & $61.1 \pm 13.05$ \\
\hline Group 5(MS) & $23.8 \pm 6.96$ & $35.2 \pm 7.42$ & $59 \pm 12.03$ \\
\hline Group 6(MD) & $23.2 \pm 5.22$ & $29.2 \pm 6.57$ & $52.4 \pm 10.41$ \\
\hline
\end{tabular}

Where $\mathrm{T} 1$ is the time taken from removal of face mask and insertion of laryngoscope blade between the teeth to visualization of vocal cords and noting the Cormack and Lehane grading and here T2 is the time taken from visualization of vocal cords and passing the endotracheal tube in the trachea to confirmation of its tracheal placement by appearance of mist in the endotracheal tube, chest wall movement, etc.

Table 4shows that the mean time taken for laryngoscopy(T1), for intubation (T2) and total duration for successful intubation in all six Groups. There was statistically significant difference in the mean duration taken for laryngoscopy amongst the groups i.e. $\mathrm{p}$ value is $<0.05$. McCoy group showing significant less time than Truview groups.

Table 5:Comparison of Number of attempts required for intubation between the groups.

\begin{tabular}{|c|c|c|c|c|c|c|c|c|c|c|}
\hline $\begin{array}{c}\text { No. of } \\
\text { Attempts }\end{array}$ & $\begin{array}{l}\text { Gr } \\
\text { (N } \\
\text { No }\end{array}$ & $\begin{array}{l}\text { 1(TM) } \\
\% \\
\%\end{array}$ & & $\begin{array}{l}\text { (TS) } \\
\% \\
\end{array}$ & & $\begin{array}{l}3(\mathrm{TD}) \\
\%\end{array}$ & & $\begin{array}{l}\text { p4(MM) } \\
\text { 50) } \\
\%\end{array}$ & $\begin{array}{l}\text { Group5(MS) } \\
(\mathrm{N}=50) \\
\text { No. \% }\end{array}$ & $\begin{array}{l}\text { Group6(MD) } \\
(\mathrm{N}=50) \\
\text { No. } \%\end{array}$ \\
\hline 1 & 45 & 90 & 46 & 92 & 43 & 86 & 46 & 92 & 96 & 90 \\
\hline 2 & 5 & 10 & 4 & 8 & 7 & 14 & 4 & 8 & 24 & 10 \\
\hline
\end{tabular}

table $\mathbf{5}$ shows that number of attempts required for successful intubation in Groups. Groups are comparable in terms of attempt taken.

Table 6:Comparison of Complications between the groups

\begin{tabular}{|c|c|c|c|c|c|c|}
\hline Complications & $\begin{array}{l}\text { Group1 } \\
\text { (TM) } \\
\text { No } \%\end{array}$ & $\begin{array}{l}\text { Group2 } \\
\text { (TS) } \\
\text { No } \%\end{array}$ & $\begin{array}{l}\text { Group3 } \\
\text { (TD) } \\
\text { No } \%\end{array}$ & $\begin{array}{l}\text { Group4 } \\
\text { (MM) } \\
\text { No \% }\end{array}$ & $\begin{array}{l}\text { Group5 } \\
\text { (MS) } \\
\text { No } \%\end{array}$ & $\begin{array}{l}\text { Group6 } \\
\text { (MD) } \\
\text { No } \%\end{array}$ \\
\hline Bleeding & \begin{tabular}{|ll}
5 & 10 \\
\end{tabular} & $\begin{array}{ll}4 & 8 \\
\end{array}$ & 36 & 24 & 12 & 3 \\
\hline Lip Trauma & 24 & 1 & $\begin{array}{ll}24 \\
\end{array}$ & 16 & 3 & 3 \\
\hline Tooth Injury & 4 & 1 & 1 & 14 & 2 & 1 \\
\hline
\end{tabular}

table 6 shows the rate of complications in Groups like bleeding, lip trauma, tooth injury.

\section{Discussion}

It is the primary responsibility of an anesthesiologist to manage the airway under anesthesia. There are well known disastrous outcomes with failed or difficult tracheal intubation following the induction of general anesthesia. An American Society of Anesthesiologists close claim analysis of adverse outcomes associated with anesthesia showed that the most common cause of serious injury was due to inadequate ventilation (38\%), esophageal intubation $(18 \%)$ and difficult tracheal intubation $(17 \%)^{6}$.Preoperative airway evaluation of patients would decrease the rate of anesthesia related adverse respiratory event. But no test is $100 \%$ sensitive and specific. So some difficult tracheal intubations are missed and some false positive may occur. An unexpected difficult intubation is always possible for which difficult intubation drill has been described. It includes use of different types of laryngoscopes like McCoy and Truview in conjunction with stylet and gum elastic bougie. Also airway management in patients with full stomach possess challenge to anesthesiologist. To prevent regurgitation of gastric contents, application of cricoid pressure has become a standard practice. However, applying cricoid pressure may cause difficulty with tracheal intubation by distorting larynx. 
The aim of the study was to compare the ease of tracheal intubation facilitated by the use of McCoy or Truview laryngoscope with malleable, straight, or directable stylet. Demographic data in terms of age and sex is evenly distributed in groups. ASA grade I and II patient among groups are comparable number. Airway Assessment done with Mallampati Classification,Mentohyoid distance,Mentothyroid distance,Mentosternal distance are comparable among groups

J.B.Li, Y.C.Xiong et al. ${ }^{7}$.In their study of 200 patients shows that overall Total Intubation time in Macintosh group was $34 \mathrm{secs}$ and in Truview group was $51 \mathrm{secs.M.A.Mallik,} \mathrm{C.H.Maharaja}{ }^{8}$.In their similar study of 120 patients shows the overall intubation time in Macintosh group was 13.9 99.2 secs, in the Truview group the Intubation time was $22.5 \pm 7.5$ secs.Gataure, P. S., Vaughan et al. ${ }^{9}$ in a study of 100 patients found mean time taken for intubation in bogie group in first attempt was $14.4 \mathrm{sec}$ and in second attempt it was 30.1 sec. It was $15.1 \mathrm{sec}$ in first attempt and $36.6 \mathrm{sec}$ in second attempt in stylet group. This difference was statistically significant and $\mathrm{p}$ value was less than 0.05 . Takashi Noguchi, Kazunori Koga et al. ${ }^{10}$ found that, T1 i.e. time from removal of face mask to insertion of gum elastic bougie in trachea was $14 \pm 2$ seconds and $19 \pm 3$ seconds was T2 i.e. time taken from insertion of gum elastic bougie to confirming successful tracheal intubation, for bougie group. Mean time taken for intubation $(\mathrm{T} 1+\mathrm{T} 2)$ was $33 \pm 4 \mathrm{sec}$ for bougie group and $33 \pm 8$ sec for stylet group.In our study,amongst the McCoy group,Group 6(with Directable stylet) patients were intubated in least timei.e52.4 \pm 10.41 secs. Thus when all the groups were compared together for the total duration taken for intubation,Group 6(McCoy with Directable stylet) patients were intubated in the least time as compared to other groups,followed by Group 5(McCoy with Straight stylet), followed by Group 4(McCoy with Malleable stylet), followed by Group 3(Truview with Directable stylet), followed by Group 2 (Truview with Straight stylet), followed by Group 1(Truview with Malleable stylet).Thus with the use of Directable stylet the intubation time was reduced in both the Truview and the McCoy groups. The difference was statistically significant and was comparable to above studies.

Nishant Kumar, KapilLamba et al. ${ }^{11}$ found that the Macintosh group $85 \%$ patients were intubated in the $1^{\text {st }}$ attempt and $15 \%$ patients were intubated in the $2^{\text {nd }}$ attempt, in the McCoy group $95 \%$ patients were intubated in the $1^{\text {st }}$ attempt and $5 \%$ patients were intubated in the $2^{\text {nd }}$ attempt, in the Truview group $85 \%$ patients were intubated in the $1^{\text {st }}$ attempt and $15 \%$ patients were intubated in the $2^{\text {nd }}$ attempt. Gataure, P. S.et al. ${ }^{9}$ shows that success rate at first attempt was $82 \%$ in bougie group and $48 \%$ in stylet group $(\mathrm{p}<0.001)$. Success rate after 2 attempts in the two groups were $96 \%$ and $66 \%$ respectively $(\mathrm{p}<0.001)$. There were only two patients in bougie group in whom tracheal intubation failed after two attempts while this no. was 17 in stylet group which were successfully intubated using bougie. In our study in the McCoy group when the patients were compared with respect to the number of attempts required for intubation Group 5(with Straight stylet) was the best, followed by Group 4(with malleable stylet), followed by Group 6(with Directable stylet). Similarly when patients among the Truview group were compared for the number of attempts, Group 2(with Straight Stylet) was best,followed by Group 1(withMalleable stylet), followed by Group 3(with Directable stylet).Thus when all the groups were compared together with respect to the number of attempts, Group 5 was best followed by Group4 followed by Group 2 and Group 1, followed by Group 3 and Group 6.

Ramesh T Timanaykar et $\mathrm{al}^{12}$.found In their study of 200 patients,84\%/14\%/2\%/0\% patients had CL grading of $1 / 2 / 3 / 4$ respectively in the Truview group and $79 \% / 17 \% / 4 \% / 0 \%$ patients were belonging to CL grade of $1 / 2 / 3 / 4$ respectively in the Macintosh group.Nishant Kumar et al(2010) ${ }^{11}$.In this study of 60 patients, $50 \% / 50 \%$ patients were belonging to CL grade $1 / 2$ in the Macintosh group, $60 \% / 40 \%$ patients were belonging to CL grade $1 / 2$ in the McCoy group, $100 \%$ patients were belonging to CL grade 1 in the Truview group. In our study, in the McCoy group, without tip elevation 34.67\%/54\%/11.33\% patients were belonging to the CL grade of $1 / 2 / 3$ whereas $68 \% / 32 \%$ patients were belonging to the CL grade $1 / 2 / 3$ when the tip of the blade was elevated.

In the Truview group, withoutcricoids pressure, $23.33 \% / 66 \% / 10.67 \%$ patients were belonging to the CL grade $1 / 2 / 3$ respectively, whereas when the cricoids pressure was applied $61.33 \% / 38.67 \% / 0 \%$ patients were belonging to the CL grade 1/2/3 respectively. Thus in the McCoy group, $44.67 \%$ patients had shown improvement in the CL grading when the tip was elevated whereas in $55.33 \%$ patients there was no improvement in the CL grading.In the Truview group,48.67\% patients had shown improvement in the CL grading and in $51.34 \%$ patients there was no improvement. Rate of complications in Goup1(TM) was $18 \%$ which included bleeding(10\%),lip trauma(4\%), tooth injury(4\%), in Group 2(TS) was $12 \%$ which included bleeding( $8 \%$ ), lip trauma(2\%), tooth injury(2\%), in Group3(TD) was $12 \%$ which included bleeding(6\%),lip trauma $(4 \%)$, tooth injury( $2 \%)$, in Group 4(MM) was bleeding $(4 \%)$, lip trauma(16\%), tooth injury(14\%), in Group5 (MS) was bleeding(2\%), lip trauma(6\%),tooth injury(4\%), in Group6(MD) was $14 \%$ which included bleeding $(6 \%)$,lip trauma( $6 \%)$,tooth injury $(2 \%)$. 


\section{Conclusion}

Endotracheal intubation is a skill developed and perfected over years.Our study was conducted in a tertiary center.During the study,intubation was performed by individuals with varying degree of experience \& expertise in intubation.The study was having nearly equal distribution of person with different intubation skills over the 6 groups.

In this prospective randomized clinical study, we observed that the duration of intubation was prolonged in the Truview group as compared to the McCoy group but the laryngoscopic optimal view which was determined by Cormack-Lehane grading was better with the Truview group.Amongst the stylet the directable stylet reduced the duration of intubation in both the McCoy and the Truview group as compared to malleable and straight stylet.The number of patients who were intubated in the $1^{\text {st }}$ attempt were more in the McCoy group as compared to the Truview group. Also there was no statistically significant difference between the rates of complications amongst the groups. So anesthesiologist during learning of newer technique or instrument handling for difficult intubation should practice this regularly so that when emergency situation arises they should be confident and quick to use this with minimum ease of handling.

\section{Bibliography}

[1]. Wilson ME.predicting difficult intubation (Editorial) Br J Anaesthesia 1993;71:333-4

[2]. .Melker RJ. Airway devices and their application. In : Kirby RR, Gravenstein N, Lobato EB, Gravenstein JS ( Eds). Clinical Anaesthesia Practice, $2^{\text {nd }}$ ed. Philadelphia: W.B. Saunders Co.2001;303-28

[3]. Latto, M. Stacey, J. Mecklenburgh and R.S. Vaughan (2002); Survey of use of gum elastic bougie in clinical practice. Anaesthesia 2002; 57,379-84

[4]. McCarroll SM, Lamont BJ, Buckland MR, Yates APB, The gum elastic bougie :old but still useful(Letter). Anaesthesiology 1988; 68:643-4

[5]. Dorsh JA, Dorsh SE. Laryngoscopes. In: Understanding Anaesthesia Equipment, 4th edn. Baltimore: Williams \& Wilkins, 1998: 505-56

[6]. Caplan RA, Posner KL, Ward RJ, Cheney FW. Adverse respiratory events in anaesthesia: a closed claims analysis. Anaesthesiology. 1990 May; 72(5):828-33.

[7]. Li Xiong YC, Wang XL, et al. An evaluation of the Truview EVO2 laryngoscope. Anaesthesia 2007; 62:940-31.

[8]. M. A. Malik, C. H. Maharaj, B. H. Harte and J. G. Laffey. Comparison of Macintosh, Truview EVO2, Glidescope, and Airwayscope laryngoscope use in patients with cervical spine immobilization

[9]. GATAURE, P. S., VAUGHAN, R. S. and LATTO, I. P. (1996), simulated difficult intubation. Anaesthesia, 51: 935-938

[10]. Takashi Noguchi, Kazunori Koga and Yousuke Shiga C.J.A.(2003); The gum elastic bougie eases reacheal intubation while applying cricoid pressurecompared to stylet.

[11]. Nisahnt Kumar et al.A randomised study of Macintosh, McCoy and Truview EVO2 laryngoscope in the intubation scenario:Comparison.J.AnaesthClinPharmacol 2010;26(1):64-68

[12]. Ramesh T Timanaykaretal.A randomized controlled study to evaluate and compare Truview blade with Macintosh blade for laryngoscopy and intubation under general anaesthesia.J. Anaesthesiology Clin Pharmacol.2011 Apr-Jun;27(2):199-204.

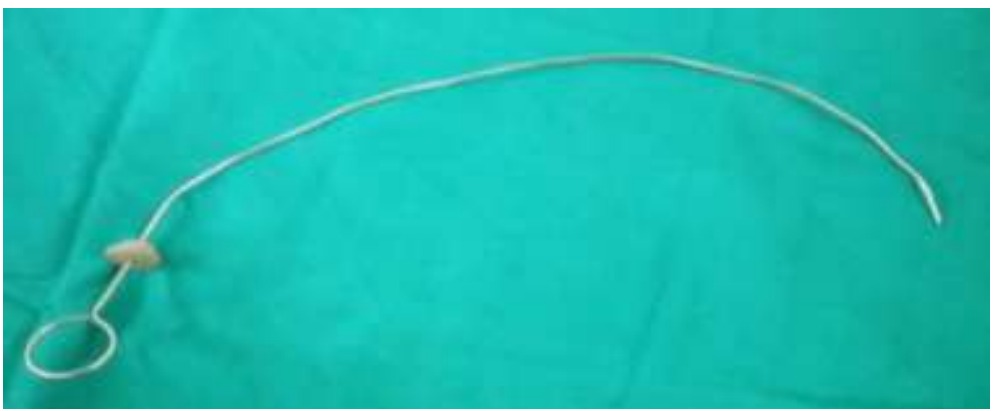

Figure 1:malleablestylet

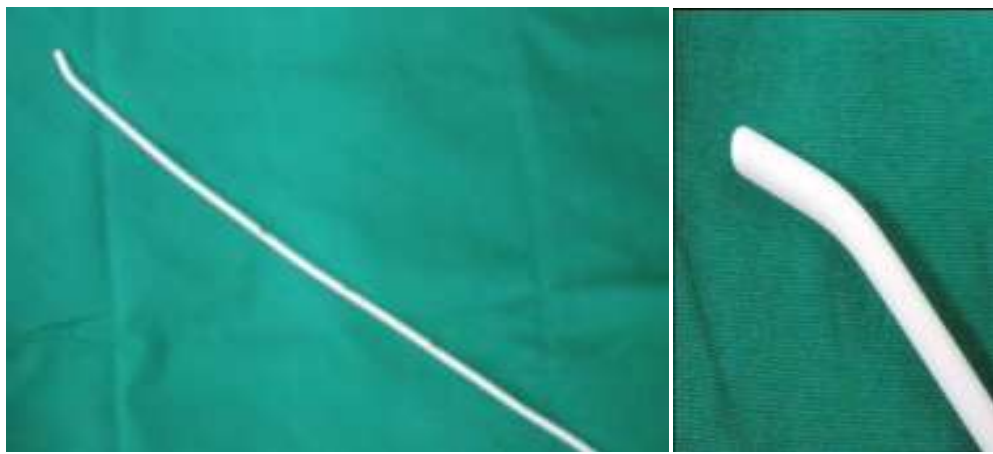

Figure 2: bougie (straight stylet) 


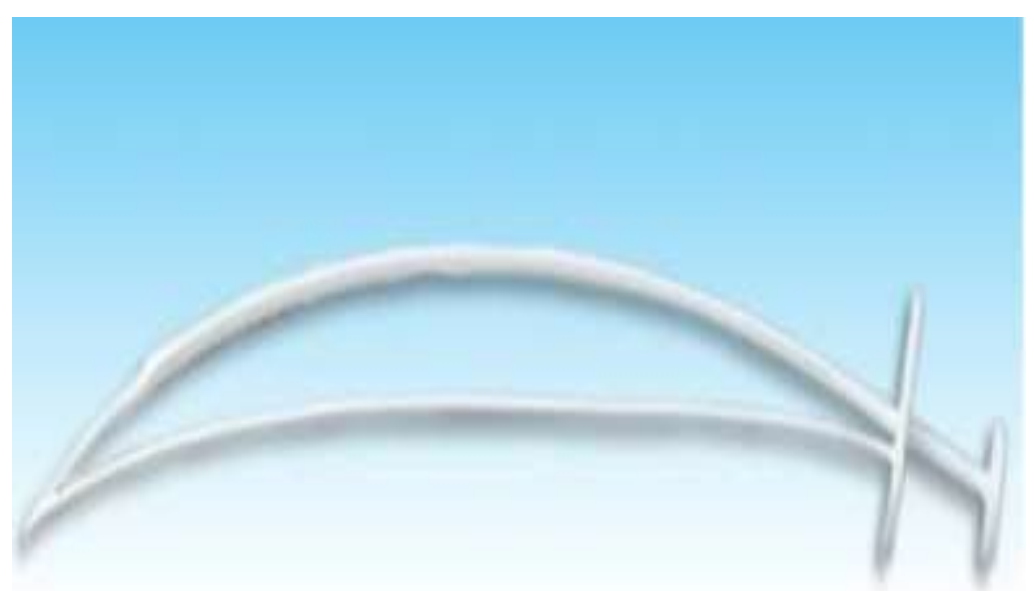

Figure 3:Directable stylet

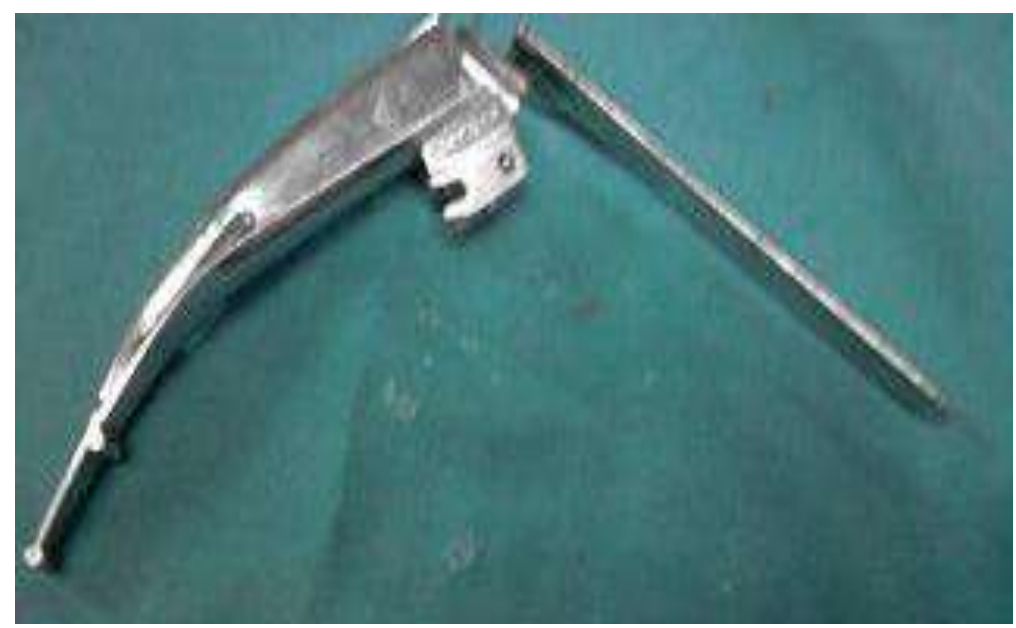

Figure 4: McCoy blade

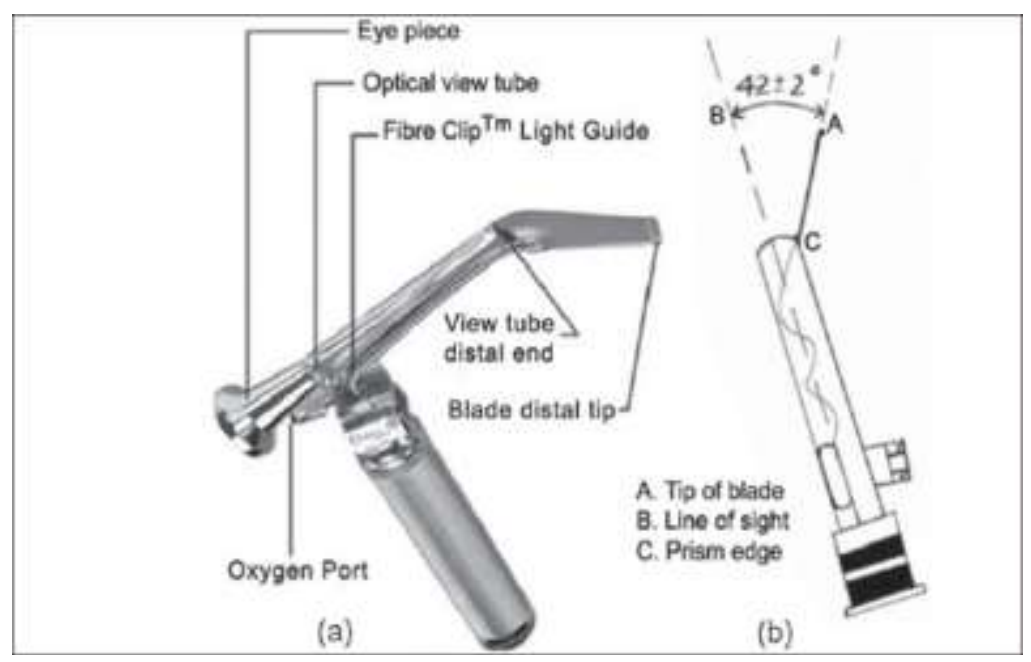

Figure 5:Truview laryngoscope 